\title{
Center variation and outcomes associated with delayed sternal closure after stage 1 palliation for hypoplastic left heart syndrome
}

\author{
Jason N. Johnson, MD, ${ }^{a}$ James Jaggers, MD, ${ }^{b}$ Shuang Li, MS, ${ }^{c}$ Sean M. O’Brien, PhD, ${ }^{c}$ \\ Jennifer S. Li, MD, MHS, ${ }^{\text {a,c }}$ Jeffrey P. Jacobs, MD, ${ }^{d}$ Marshall L. Jacobs, MD, ${ }^{e}$ Karl F. Welke, MD, ${ }^{f}$ \\ Eric D. Peterson, MD, MPH, ${ }^{c}$ and Sara K. Pasquali, $\mathrm{MD}^{\mathrm{a}, \mathrm{c}}$
}

\begin{abstract}
Objective: There is debate whether primary or delayed sternal closure is the best strategy after stage 1 palliation for hypoplastic left heart syndrome. We describe center variation in delayed sternal closure after stage 1 palliation and associated outcomes.
\end{abstract}

\begin{abstract}
Methods: Society of Thoracic Surgeons Congenital Database participants performing stage 1 palliation for hypoplastic left heart syndrome from 2000 to 2007 were included. We examined center variation in delayed sternal closure and compared in-hospital mortality, prolonged length of stay (length of stay $>6$ weeks), and postoperative infection in centers with low ( $\leq 25 \%$ of cases), middle ( $26 \%-74 \%$ of cases), and high ( $\geq 75 \%$ of cases) delayed sternal closure use, adjusting for patient and center factors.
\end{abstract}

Results: There were 1283 patients (45 centers) included. Median age at surgery was 6 days (interquartile range, 4-9 days), and median weight at surgery was $3.2 \mathrm{~kg}$ (interquartile range, $2.8-3.5 \mathrm{~kg}$ ); $59 \%$ were male. Delayed sternal closure was used in $74 \%$ of cases (range, $3 \%-100 \%$ of cases/center). In centers with high $(n=23)$ and middle $(n=17)$ versus low $(n=5)$ delayed sternal closure use, there was a greater proportion of patients with prolonged length of stay and infection, and a trend toward increased in-hospital mortality in unadjusted analysis. In multivariable analysis, there was no difference in mortality. Centers with high and middle delayed sternal closure use had prolonged length of stay (odds ratio, 2.83; 95\% confidence interval, 1.46-5.47; $P=.002$ and odds ratio, 2.23; confidence interval, 1.17-4.26; $P=.02$, respectively) and more infection (odds ratio, 2.34; confidence interval, $1.20-4.57 ; P=.01$ and odds ratio, 2.37; confidence interval, 1.36-4.16; $P=.003$, respectively).

Conclusion: Use of delayed sternal closure after stage 1 palliation varies widely. These observational data suggest that more frequent use of delayed sternal closure is associated with longer length of stay and higher postoperative infection rates. Further evaluation of the risks and benefits of delayed sternal closure in the management of these complex infants is necessary. (J Thorac Cardiovasc Surg 2010;139:1205-10)

Delayed sternal closure (DSC) after stage 1 palliation for hypoplastic left heart syndrome (HLHS) is used by many centers. Capillary leak syndrome is common after cardiopul-

\footnotetext{
From the Divisions of Pediatric Cardiology ${ }^{a}$ and Cardiothoracic Surgery ${ }^{b}$ in the Departments of Pediatrics and Surgery, Duke University Medical Center, and Duke Clinical Research Institute, ${ }^{\mathrm{c}}$ Durham, NC; Division of Thoracic and Cardiovascular Surgery, The Congenital Heart Institute of Florida, All Children's Hospital and Children's Hospital of Tampa, University of South Florida College of Medicine, ${ }^{\mathrm{d}} \mathrm{St}$ Petersburg and Tampa, Fla; Department of Pediatric and Congenital Heart Surgery, Cleveland Clinic, Cleveland, Ohio; and Division of Cardiothoracic Surgery, ${ }^{\mathrm{f}}$ Oregon Health and Science University, Portland, Ore.

Disclosures: None.

Dr Pasquali receives grant support (KL2 RR024127-02) from the National Center for Research Resources, a component of the National Institutes of Health (NIH) and NIH Roadmap for Medical Research, and from the American Heart Association Mid-Atlantic Affiliate Clinical Research Program. The contents of this publication are solely the responsibility of the authors and do not necessarily represent the official view of National Center for Research Resources, NIH, or American Heart Association.

Received for publication June 23, 2009; revisions received Oct 14, 2009; accepted for publication Nov 14, 2009; available ahead of print Feb 18, 2010

Reprint requests: Sara K. Pasquali, MD, Assistant Professor of Pediatrics, Division of Cardiology, Department of Pediatrics, Duke University Medical Center, Duke Clinical Research Institute, PO Box 17969, Durham, NC 27715 (E-mail: sara.pasquali@ duke.edu).

$0022-5223 / \$ 36.00$

Copyright (c) 2010 by The American Association for Thoracic Surgery

doi:10.1016/j.jtcvs.2009.11.029
}

monary bypass and characterized by increased vascular permeability, generalized edema, impaired pulmonary function, coagulopathy, and cardiac dysfunction. ${ }^{1}$ Sternal closure immediately after surgery can be associated with cardiac compression, decreased ventricular compliance, and reduced cardiac output, further compromising hemodynamic and respiratory status. ${ }^{2,3}$ Thus, the aim of DSC is to minimize postoperative hemodynamic and respiratory instability, and to provide ready access to sites of persistent bleeding. DSC may be used routinely, per surgeon or center preference, or selectively, secondary to concern for hemodynamic instability after sternal closure.

However, outcomes associated with DSC are unclear, and a recent survey suggested significant variation in use of DSC after stage 1 palliation. ${ }^{4}$ Single-center studies have reported conflicting results regarding the impact of DSC on outcomes, including survival to hospital discharge and morbidities such as postoperative infection. ${ }^{5-14}$ These studies have been limited by small sample size and in some cases lack of appropriate control groups.

The purpose of this study was to describe center variation in the use of DSC after stage 1 palliation for HLHS and to evaluate postoperative outcomes associated with DSC using 


\author{
Abbreviations and Acronyms \\ $\mathrm{CI}=$ confidence interval \\ DSC $=$ delayed sternal closure \\ HLHS $=$ hypoplastic left heart syndrome \\ $\mathrm{OR}=$ odds ratio \\ STS $=$ Society of Thoracic Surgeons
}

the Society of Thoracic Surgeons (STS) Congenital Heart Surgery Database.

\section{MATERIALS AND METHODS \\ Data Source}

As previously described, the STS Congenital Heart Surgery Database collects operative and perioperative data on all patients undergoing congenital heart surgery at participating centers. ${ }^{15}$ Data collected include demographics, diagnosis, noncardiac abnormalities, preoperative factors, intraoperative details, surgical procedure performed, postoperative complications, and in-hospital mortality. The Duke Clinical Research Institute serves as the data collection and management organization for the STS National Databases. This study was approved by the Duke Institutional Review Board.

\section{Study Population}

Infants who underwent stage 1 palliation (Norwood procedure with modified Blalock-Taussig shunt or right ventricle to pulmonary artery conduit) for HLHS between January 2000 and December 2007 were included. Centers with more than $15 \%$ missing data on mortality, length of stay, or postoperative complications, and those with less than 5 eligible cases were excluded. Individual patients $(n=7)$ from remaining centers with missing data on mortality or length of stay were then excluded, leaving a final population of 1283 patients from 45 centers. Missing data for other variables in the final study population were rare $(<0.8 \%$ for all).

\section{Data Collection}

Data on use of DSC were collected. Of note, the STS database does not distinguish between "routine" versus "selective" DSC. Patient demographic information (age, weight, length, and gender) and data on any noncardiac abnormalities were collected, as defined in the database by asplenia, polysplenia, Down syndrome, Turner syndrome, DiGeorge, Williams-Beuren syndrome, Alagille syndrome, 22q11 deletion, rubella, Marfan syndrome, or any other chromosomal/syndromic abnormality. Data collected regarding preoperative factors included preoperative shock, acidosis, arrhythmia, mechanical circulatory support (use of extracorporeal membrane oxygenation or ventricular assist device), mechanical ventilatory support (of note, the database does not distinguish between mechanical ventilatory support required for respiratory failure vs that used during transport or in routine preoperative management), renal failure, sepsis, and neurologic deficit. Operative data collected included duration of cardiopulmonary bypass, crossclamp, and circulatory arrest. The data from the era of collection did not specify the use of regional cerebral perfusion. Postoperative data collected included infection, length of stay, and in-hospital mortality. Postoperative infection included sepsis (the current definition of which in the database requires a positive blood culture and excludes line infection), mediastinitis, wound infection, wound dehiscence, and endocarditis. Data on center characteristics were also collected, including center region and annual surgical volume of stage 1 palliation for HLHS.

\section{Analysis}

Data were summarized using frequencies and percentages for categoric variables and median and interquartile range for continuous variables. Centers were characterized on the basis of the proportion of cases at each center for which DSC was used: low ( $\leq 25 \%$ of cases), middle $(26 \%-74 \%$ of cases), and high ( $\geq 75 \%$ of cases). Patient and center characteristics were compared across the DSC groups using chi-square and Kruskal-Wallis tests for categoric and continuous variables, respectively. The relationship between preoperative factors (any of above) and cardiopulmonary bypass time was evaluated using the Wilcoxon rank-sum test. A generalized estimating equations logistic regression analysis was used to evaluate the relationship between center average annual volume of stage 1 palliations performed for HLHS and DSC use.

Outcomes associated with DSC were evaluated using a center-level analysis in an attempt to minimize the impact of patient confounders and to compare outcomes at centers with "routine" or elective use of DSC versus those that did not use DSC as frequently. In-hospital mortality, prolonged postoperative length of stay (defined as length of stay $>6$ weeks, which was the upper quartile of length of stay for the entire cohort: median, 22 days; interquartile range, 13-41 days) and postoperative infection (as defined above) were compared across centers with low, middle, and high DSC use in univariable and multivariable logistic regression, adjusting for patient age, weight, preoperative factors (as listed above), year of surgery, and center volume. The generalized estimating equations method was used to account for correlation between outcomes of patients at the same center. Missing data were imputed as "not present" for categoric variables, which was the most common value, or the median of non-missing values for continuous variables. Finally, a sensitivity analysis was performed to evaluate the impact of preoperative factors on outcome. Unadjusted and adjusted odds ratios (ORs) and 95\% confidence intervals (CIs) are presented. All analyses were conducted using SAS version 8.2 (SAS Institute Inc, Cary, NC).

\section{RESULTS}

A total of 1283 patients from 45 centers were included. Median age at surgery was 6 days (4-9 days), and median weight at surgery was $3.2 \mathrm{~kg}(2.8-3.5 \mathrm{~kg}) ; 59 \%$ were male. DSC was used in $74 \%$ of cases overall (range, $3 \%-$ $100 \%$ of cases per center; Figure 1). Patient characteristics,

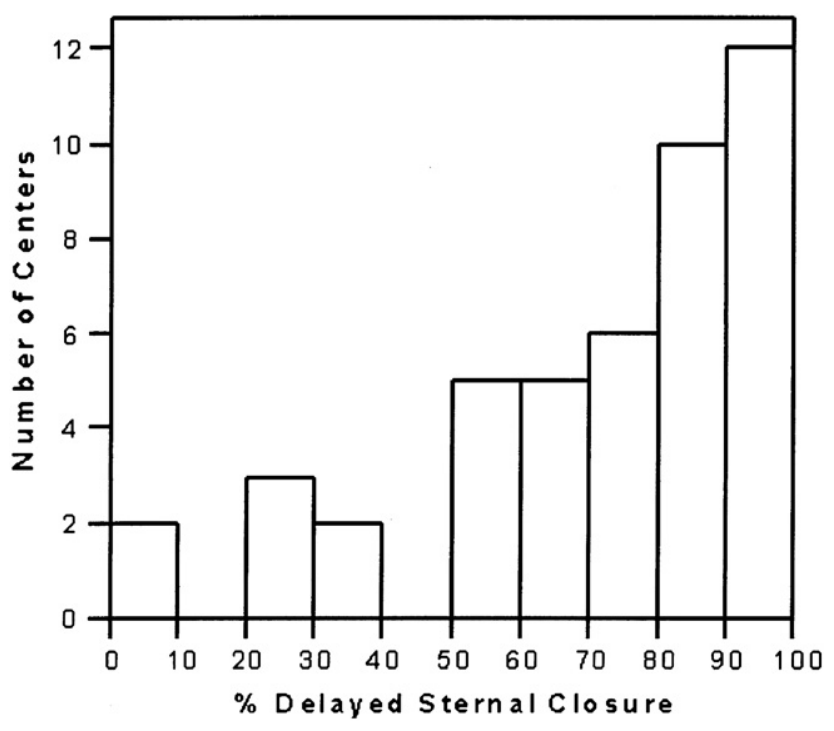

FIGURE 1. Distribution of center use of DSC. 
TABLE 1. Patient characteristics

\begin{tabular}{|c|c|c|c|}
\hline & \multicolumn{3}{|c|}{ DSC use } \\
\hline & $\begin{array}{c}\text { Low } \\
5 \text { centers }(n=111)\end{array}$ & $\begin{array}{c}\text { Middle } \\
17 \text { centers }(n=406)\end{array}$ & $\begin{array}{c}\text { High } \\
23 \text { centers }(n=766)\end{array}$ \\
\hline \multicolumn{4}{|l|}{ Patient characteristics } \\
\hline Age, d & $8(5-24)$ & $6(4-8)$ & $6(4-8)$ \\
\hline Weight, kg & $3.3(2.9-3.8)$ & $3.2(2.8-3.5)$ & $3.1(2.8-3.5)$ \\
\hline Gender, male & $73(65.8 \%)$ & $240(59.1 \%)$ & $445(58.1 \%)$ \\
\hline $\begin{array}{l}\text { Noncardiac abnormality/ } \\
\text { syndrome }\end{array}$ & $19(17.1 \%)$ & $75(18.5 \%)$ & $126(16.5 \%)$ \\
\hline \multicolumn{4}{|l|}{ Preoperative factors } \\
\hline Shock & $5(4.5 \%)$ & $13(3.2 \%)$ & $32(4.2 \%)$ \\
\hline Acidosis & $8(7.2 \%)$ & $44(10.8 \%)$ & $133(17.4 \%)$ \\
\hline $\begin{array}{l}\text { Mechanical circulatory } \\
\text { support }\end{array}$ & $0(0.0 \%)$ & $5(1.2 \%)$ & $7(0.9 \%)$ \\
\hline $\begin{array}{l}\text { Mechanical ventilatory } \\
\text { support }\end{array}$ & $24(21.6 \%)$ & $156(38.4 \%)$ & $338(44.1 \%)$ \\
\hline Renal failure & $2(1.8 \%)$ & $8(2.0 \%)$ & $10(1.3 \%)$ \\
\hline Septicemia & $3(2.7 \%)$ & $8(2.0 \%)$ & $12(1.6 \%)$ \\
\hline Neurologic deficit & $1(0.9 \%)$ & $7(1.7 \%)$ & $8(1.0 \%)$ \\
\hline \multicolumn{4}{|l|}{ Operative data } \\
\hline CPB time, min & $192(143-266)$ & $160(137-193)$ & $134(79-169)$ \\
\hline Crossclamp time, $\min$ & $65(47-95)$ & $55(42-71)$ & $46(1-62)$ \\
\hline $\begin{array}{l}\text { Circulatory arrest } \\
\text { time, } \min ^{*}\end{array}$ & $12(0-41)$ & $7(0-34)$ & $34(4-48)$ \\
\hline
\end{tabular}

$D S C$, Delayed sternal closure; $C P B$, cardiopulmonary bypass. *Use of regional cerebral perfusion is not currently captured in the STS Database.

preoperative factors, and operative data in the low, middle, and high DSC groups are displayed in Table 1. The weight at surgery and presence of any noncardiac abnormality were similar across groups. The distribution of various preoperative factors was similar across groups as shown in Table 1, with the exception of acidosis and preoperative mechanical ventilatory support. In regard to operative data, those with more frequent use of DSC had shorter cardiopulmonary bypass times (Table 1). The presence of any of the preoperative factors listed in Table 1 was associated with shorter cardiopulmonary bypass time (145 minutes [93-178] vs $151 \mathrm{~min}$ utes [123-184], $P<.0001)$.

On evaluation of center characteristics, there was no association between center average annual volume of stage 1 palliations performed for HLHS and the proportion who received DSC $(P=.1)$. There was no evidence of variation in the frequency of DSC across geographic regions.

Unadjusted outcomes are shown in Table 2 and Figure 2. In unadjusted analysis, there was a trend toward greater inhospital mortality and a significantly increased proportion with postoperative infection and prolonged length of stay in the middle and high DSC groups compared with the low DSC group. Length of stay was 17 days (8-26 days) in the low DSC group, 21 days (12-40 days) in the middle DSC group, and 24 days (14-43 days) in the high DSC group $(P<.001)$. Information concerning type of postoperative infection is shown in Table 3.
TABLE 2. Unadjusted and adjusted odds ratios for outcomes associated with center use of delayed sternal closure

\begin{tabular}{|c|c|c|c|c|}
\hline & \multicolumn{2}{|c|}{ Unadjusted } & \multicolumn{2}{|c|}{ Adjusted } \\
\hline & OR $(95 \%$ CI $)$ & $P$ value & OR $(95 \%$ CI $)$ & $P$ value \\
\hline \multicolumn{5}{|c|}{ In-hospital mortality } \\
\hline \multicolumn{5}{|c|}{ DSC use: } \\
\hline Low & Reference & & & \\
\hline Middle & $\begin{array}{c}1.90 \\
(0.93-3.89)\end{array}$ & .08 & $\begin{array}{c}1.28 \\
(0.80-2.07)\end{array}$ & .31 \\
\hline High & $\begin{array}{c}1.63 \\
(0.85-3.11)\end{array}$ & .14 & $\begin{array}{c}1.08 \\
(0.68-1.71)\end{array}$ & .74 \\
\hline \multicolumn{5}{|c|}{ Postoperative infection } \\
\hline \multicolumn{5}{|c|}{ DSC use: } \\
\hline Low & Reference & & & \\
\hline Middle & $\begin{array}{c}2.82 \\
(1.53-5.21)\end{array}$ & .001 & $\begin{array}{c}2.37 \\
(1.36-4.16)\end{array}$ & .003 \\
\hline High & $\begin{array}{c}2.75 \\
(1.28-5.92)\end{array}$ & .009 & $\begin{array}{c}2.34 \\
(1.20-4.57)\end{array}$ & .01 \\
\hline \multicolumn{5}{|c|}{ Prolonged LOS } \\
\hline \multicolumn{5}{|c|}{ DSC use: } \\
\hline Low & Reference & & & \\
\hline Middle & $\begin{array}{c}2.09 \\
(1.07-4.05)\end{array}$ & .03 & $\begin{array}{c}2.23 \\
(1.17-4.26)\end{array}$ & .02 \\
\hline High & $\begin{array}{c}2.59 \\
(1.37-4.91)\end{array}$ & .004 & $\begin{array}{c}2.83 \\
(1.46-5.47)\end{array}$ & .002 \\
\hline
\end{tabular}

$O R$, Odds ratio; $C I$, confidence interval; $D S C$, delayed sternal closure; $L O S$, length of stay 


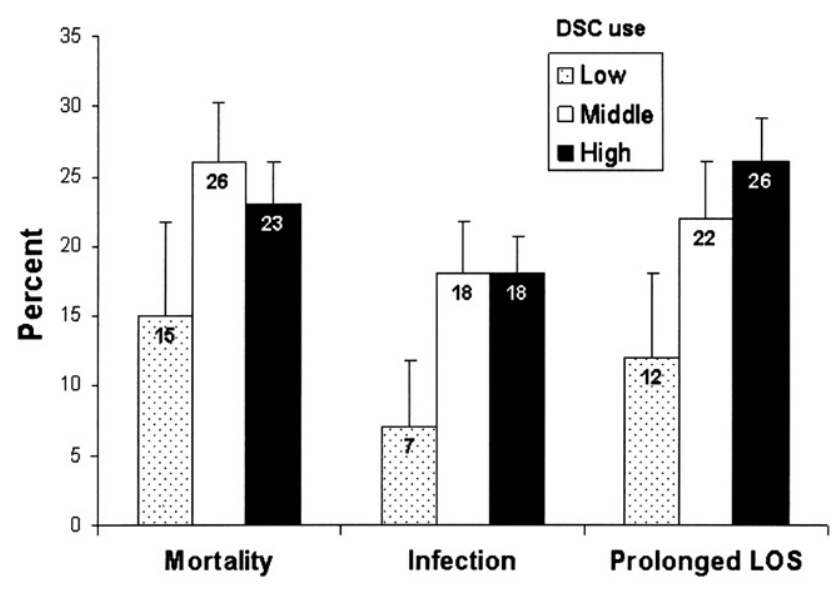

FIGURE 2. Unadjusted outcomes associated with center use of DSC. Comparison of the middle and high DSC groups versus low DSC group: $P=.08$ and $P=.14$ for mortality, $P=.001$ and $P=.009$ for infection, and $P=.03$ and $P=.004$ for prolonged length of stay, respectively. Lines extending from the bars indicate $95 \%$ CIs. DSC, Delayed sternal closure; $L O S$, length of stay.

In multivariable analysis, there was no significant difference in in-hospital mortality among groups, but postoperative infection and prolonged length of stay were significantly greater in the middle and high DSC groups compared with the low DSC group (Table 2).

To evaluate the impact of preoperative factors on outcome, preoperative factors were removed from the models and the analysis was repeated, with similar results (vs Table 2): in-hospital mortality (middle DSC group: OR, 1.35; 95\% CI, $0.83-2.22 ; P=.23$; and high DSC group: OR, 1.21; CI, $0.77-1.90 ; P=.40$ ), infection (middle DSC group: OR, 2.49; CI, 1.40-4.40; $P=.002$; and high DSC group: OR, 2.56; CI, 1.30-5.01; $P=.006$ ), and prolonged length of stay (middle DSC group: OR, 2.30; CI, 1.17-4.52; $P=.02$; and high DSC group: OR, 2.99; CI, 1.51-5.92; $P=.002$ ).

\section{DISCUSSION}

There is debate regarding the optimal timing of sternal closure after stage 1 palliation for infants with HLHS. Although it is hypothesized that DSC may promote greater hemodynamic and respiratory stability in the postoperative period, outcomes associated with this approach are unclear. By evaluating 1283 infants with HLHS, we found that use of DSC after stage 1 palliation varied widely among 45 US centers. More frequent use of DSC was associated with prolonged length of stay and higher rates of postoperative infection. DSC was not significantly associated with in-hospital mortality.

Survival after staged palliation for patients with HLHS has improved significantly during the past 2 decades. ${ }^{16-19}$ However, evidence to guide optimal care in this patient population is still evolving. A recent survey of centers caring for infants with HLHS suggested that perioperative care varied widely by center, including differences in models of care delivery, operative techniques, medications used, feeding regimens, and type of monitoring. ${ }^{4}$ Wide variations in practice may reflect the lack of evidence to define best practices.

This prior survey also suggested variation in use of DSC after stage 1 palliation, which was confirmed in our study. ${ }^{4}$ We did not find any correlation between the use of DSC and center characteristics. In regard to patient characteristics, we found that centers who used DSC more frequently tended to report a higher prevalence of factors, such as acidosis and preoperative mechanical ventilatory support. This may reflect differences in patient preoperative status or coding of these variables. Of note, the database does not distinguish between mechanical ventilation required for respiratory failure versus that used in the routine preoperative management of these infants. However, one may hypothesize that because of the presence of these factors, these patients were "sicker" going into surgery, leading to longer cardiopulmonary bypass times, greater postoperative edema, and more frequent use of DSC. Previous studies have suggested that longer cardiopulmonary bypass times are associated with greater capillary leak and postoperative inflammation, and greater use of DSC. ${ }^{20-22}$ However, we found that patients with preoperative "risk" factors actually had shorter cardiopulmonary bypass times. Centers with more frequent use of DSC also had shorter cardiopulmonary bypass times. In addition, in a sensitivity analysis to evaluate the impact of preoperative factors on outcome, we found similar results whether or not these factors were included in our models. Thus, our data suggest that the presence of these preoperative factors

TABLE 3. Type of postoperative infection

\begin{tabular}{|c|c|c|c|c|}
\hline & \multicolumn{3}{|c|}{ DSC use } & \multirow[b]{2}{*}{$P$ value } \\
\hline & $\begin{array}{c}\text { Low } \\
5 \text { centers }(n=111)\end{array}$ & $\begin{array}{c}\text { Middle } \\
17 \text { centers }(n=406)\end{array}$ & $\begin{array}{c}\text { High } \\
23 \text { centers }(n=766)\end{array}$ & \\
\hline Wound dehiscence & $0(0 \%)$ & $10(2.5 \%)$ & $7(0.9 \%)$ & .04 \\
\hline Wound infection & $3(2.7 \%)$ & $16(3.9 \%)$ & $32(4.2 \%)$ & .76 \\
\hline Postoperative sepsis & $5(4.5 \%)$ & $55(13.6 \%)$ & $95(12.4 \%)$ & .03 \\
\hline Mediastinitis & $1(0.9 \%)$ & $2(0.5 \%)$ & $14(1.8 \%)$ & .15 \\
\hline Postoperative endocarditis & $0(0 \%)$ & $1(0.3 \%)$ & $3(0.4 \%)$ & .76 \\
\hline
\end{tabular}


or longer duration of cardiopulmonary bypass does not lead to more frequent use of DSC, and that these preoperative factors do not seem to affect the relationship between DSC and outcome. Other factors not captured in the STS Database, such as hemodynamic status at the conclusion of surgery, experience of ICU staff in managing infants who have undergone primary sternal closure, and availability of 24hour in-house surgical support, may affect center or surgeon preference for primary versus DSC. In addition, other preoperative variables, including variations in anatomic substrate such as the presence of aortic atresia or a restrictive atrial septum, may also affect outcome. ${ }^{9,23}$

Results of prior studies evaluating outcomes associated with DSC are conflicting. Studies of DSC in infants and children undergoing congenital heart surgery for a variety of defects have reported increased mortality associated with DSC. ${ }^{5,6}$ However, in these studies, DSC was only performed in patients who were hemodynamically unstable. Therefore, higher mortality in this group may be expected. In studies focusing on patients undergoing stage 1 palliation, some have found DSC to be associated with increased mortality, whereas others have not found a significant relationship. ${ }^{7-9}$ In our analysis, we did not find a significant relationship between in-hospital mortality and DSC. Despite potential alterations in hemodynamic status associated with primary sternal closure, and hypothesized benefits of DSC, a survival benefit was not evident in our analysis., 2,3

In contrast, we did find that use of DSC was associated with increased postoperative morbidity, including infection and prolonged length of stay. Prior studies regarding the relationship between DSC and postoperative infection have had mixed results. Several studies have reported no increase in mediastinitis or bloodstream infections associated with the use of DSC. ${ }^{10,11}$ However, others have shown an increase in gram-negative mediastinitis and surgical site infections. ${ }^{12-14}$ Our data show the higher rate of infection is primarily related to bloodstream infections. Previous studies evaluating the relationship of DSC with length of stay are limited. A prior single-center study in the arterial switch population reported no difference in survival, postoperative length of stay, or postoperative infection associated with DSC. ${ }^{24}$ This study was limited by small sample size $(\mathrm{n}=$ 52). It is likely that the increased frequency of postoperative infection found in our study is related to the prolonged length of stay. Postoperative infection has been shown to be associated with prolonged length of stay and increased mortality. ${ }^{13}$ Because of the limitations of the database, we were not able to evaluate the impact of DSC on duration of mechanical ventilation; however, it is likely that use of DSC is associated with longer duration of intubation, which may also affect length of stay. Alternatively, it is possible that length of stay was affected by other factors not related to DSC, such as postoperative feeding difficulties, the management of which may vary by center. Such variation would not lead to a spurious association between DSC and length of stay unless these factors differed systematically across the different categories of DSC. In addition, to reduce the potential for confounding by center-level factors, our risk model explicitly adjusted for hospital-level variables, including center volume. Finally, our analytic strategy accounts for unexplained between-hospital variation by treating observations within a hospital as clustered (correlated) observations. Perioperative morbidities, such as prolonged length of stay, also may have an impact on longerterm outcomes, because prior studies have shown prolonged hospital stay to be an independent predictor of future neurodevelopmental status in patients with HLHS. ${ }^{25}$

\section{LIMITATIONS}

This study is subject to the limitations associated with all observational investigations, including selection bias and the potential impact of confounders. We performed a center-level analysis in an attempt to minimize the impact of patient confounders and adjusted for patient and center factors in addition to accounting for within-center clustering of outcomes in our models. We also performed a sensitivity analysis to further evaluate the potential impact of patient preoperative factors on outcome.

This study is also subject to the limitations of data collected. We were unable to evaluate elective versus emergency use of DSC because this is not defined in the database. However, using a center-level analysis did allow us to compare outcomes in those with "routine", or elective (high) use of DSC versus those who did not use DSC as frequently. We were also unable to evaluate the impact of duration of time the chest is open after surgery on outcomes because this information is not uniformly captured in the database currently. The database is also limited in that institutions may differ in their coding of different variables. More uniform definitions of variables were added to the database in 2005; however, these may still be interpreted differently by different institutions. In addition, we were not able to evaluate the impact of factors such as variations in anatomic substrate, hemodynamic status at the conclusion of surgery, perioperative antibiotic or corticosteroid use, and center model of postoperative care on the relationship between DSC and outcome because these variables are not collected in the database. Finally, although this represents the largest study to date evaluating DSC in this population, our sample size may have limited our power to detect certain differences among groups.

\section{CONCLUSIONS}

This multicenter study is the largest to date evaluating use of DSC after stage 1 palliation for patients with HLHS. We found that use of DSC varies widely, although the majority of centers use DSC in more than half of cases. This observational study suggests that more frequent use of DSC is 
associated with no difference in survival, greater postoperative morbidity, including prolonged length of stay, and higher rates of postoperative infection, primarily related to sepsis. Further evaluation of the risks and benefits of DSC in the management of these complex infants is warranted, particularly in cases involving elective use of DSC. Given the wide variation in practice of DSC by institution and potential variations in other aspects of care for these infants, a trial performed in this area may need to use stratification of randomization by institution or the implementation of standardized management protocols across institutions.

\section{References}

1. Seghaye MC, Grabitz RG, Duchateau J, Busse S, Dabritz S, Koch D. Inflammatory reaction and capillary leak syndrome related to cardiopulmonary bypass in neonates undergoing cardiac operations. J Thorac Cardiovasc Surg. 1996;112:687-97.

2. McElhinney DB, Reddy VM, Parry AJ, Johnson L, Fineman JR, Hanley FL. Management and outcomes of delayed sternal closure after cardiac surgery in neonates and infants. Crit Care Med. 2000;28:1180-4.

3. Kay PH, Brass T, Lincoln C. The pathophysiology of atypical tamponade in infants undergoing cardiac surgery. Eur J Cardiothorac Surg. 1989;3:255-61.

4. Wernovsky G, Ghanayem N, Ohye RG, Bacha EA, Jacobs JP, Gaynor JW, et al. Hypoplastic left heart syndrome: consensus and controversies in 2007. Cardiol Young. 2007;17:S75-86.

5. Riphagen S, McDougall M, Tibby SM, Alphonso N, Anderson D, Austin C, et al. "Early" delayed sternal closure following pediatric cardiac surgery. Ann Thorac Surg. 2005;80:678-84.

6. Alexi-Meskishvili V, Weng Y, Uhlemann F, Lange PE, Hetzer R. Prolonged open sternotomy after pediatric open heart operation: experience with 113 patients. Ann Thorac Surg. 1995;59:379-83.

7. Hehir DA, Dominguez TE, Ballweg JA, Ravishankar C, Marino BS, Bird GL, et al. Risk factors for interstage death after stage 1 reconstruction of hypoplastic left heart syndrome and variants. J Thorac Cardiovasc Surg. 2008;136:94-9.

8. Gaynor JW, Mahle WT, Cohen MI, Ittenbach RF, DeCampli WM, Steven JM, et al. Risk factors for mortality after the Norwood procedure. Eur J Cardiothorac Surg. 2002;22:82-9.

9. Forbess JM, Cook N, Roth SJ, Serraf A, Mayer JE, Jonas RA. Ten-year institutional experience with palliative surgery for hypoplastic left heart syndrome. Risk factors related to stage 1 mortality. Circulation. 1995;92:II262-6.

10. Al-Sehly AA, Robinson JL, Lee BE, Taylor G, Ross DB, Robertson M, et al. Pediatric poststernotomy mediastinitis. Ann Thorac Surg. 2005;80:2314-20.

11. Shah SS, Kagen J, Lautenbach E, Bilker WB, Matro J, Dominguez TE, et al. Bloodstream infections after median sternotomy at a children's hospital. J Thorac Cardiovasc Surg. 2007;133:435-40.
12. Long CB, Shah SS, Lautenbach E, Coffin SE, Tabbutt S, Gaynor JW, et al. Postoperative mediastinitis in children: epidemiology, microbiology and risk factors for gram-negative pathogens. Pediatr Infect Dis J. 2005; 24:315-9.

13. Holzmann-Pazgal G, Hopkins-Broyles D, Recktenwald A, Hohrein M, Kieffer P, Huddleston C, et al. Case-control study of pediatric cardiothoracic surgical site infections. Infect Control Hosp Epidemiol. 2008;29:76-9.

14. Levy I, Ovadia B, Erez E, Rinat S, Ashkenazi S, Birk E, et al. Nosocomial infections after cardiac surgery in infants and children: incidence and risk factors. J Hosp Infect. 2003;53:111-6.

15. Curzon CL, Milford-Beland S, Li JS, O'Brien SM, Jacobs JP, Jacobs ML, et al. Cardiac surgery in infants with low birth weight is associated with increased mortality: Analysis of the Society of Thoracic Surgeons Congenital Heart Database. J Thorac Cardiovasc Surg. 2008;135:546-51.

16. Tweddell JS, Hoffman GM, Mussatto KA, Fedderly RT, Berger S, Jaquiss RD, et al. Improved survival of patients undergoing palliation of hypoplastic left heart syndrome: lessons learned from 115 consecutive patients. Circulation. 2002; 106(12 Suppl. 1):I82-9.

17. Mahle WT, Spray TL, Wernovsky G, Gaynor JW, Clark BJ III. Survival after reconstructive surgery for hypoplastic left heart syndrome: a 15-year experience from a single institution. Circulation. 2000;102:III136-41.

18. Tabbutt S, Dominguez TE, Ravishankar C, Marino BS, Gruber PJ, Wernovsky G, et al. Outcomes after the stage I reconstruction comparing the right ventricular to pulmonary artery conduit with the modified Blalock Taussig shunt. Ann Thorac Surg. 2005;80:1582-90.

19. Azakie T, Merklinger SL, McCrindle BW, Van Arsdell GS, Lee KJ, Benson LN, et al. Evolving strategies and improving outcomes of the modified Norwood procedure: a 10-year single-institution experience. Ann Thorac Surg. 2001;72: 1349-53.

20. Maehara T, Novak I, Wyse RK, Elliot MJ. Perioperative monitoring of total body water by bio-electrical impedance in children undergoing open heart surgery. Eur J Cardiothorac Surg. 1991;5:258-64.

21. Stiller B, Sonntag J, Dähnert I, Alexi-Meskishvili V, Hetzer R, Fischer T, et al. Capillary leak syndrome in children who undergo cardiopulmonary bypass: clinical outcome in comparison with complement activation and $\mathrm{C} 1$ inhibitor. Intensive Care Med. 2001;27:193-200.

22. Samir K, Riberi A, Ghez O, Ali M, Metras D, Kreitmann B. Delayed sternal closure: a life-saving measure in neonatal open heart surgery; could it be predictable? Eur J Cardiothorac Surg. 2002;21:787-93.

23. Glatz JA, Tabbutt S, Gaynor JW, Rome JJ, Montenegro L, Spray TL, et al. Hypoplastic left heart syndrome with atrial level restriction in the era of prenatal diagnosis. Ann Thorac Surg. 2007;84:1633-8.

24. Owens WA, Vitale N, Hasan A, Hamilton JRL. A policy of elective delayed sternal closure does not improve the outcome after arterial switch. Ann Thorac Surg. 2001;71:1553-5.

25. Mahle WT, Visconti KJ, Freier C, Kanne SM, Hamilton WG, Sharkey AM, et al. Relationship of surgical approach to neurodevelopmental outcomes in hypoplastic left heart syndrome. Pediatrics. 2006;117:e90-7. 